\title{
A New Study on the Parameter Relationships of Planetary Roller Screws
}

\author{
Shangjun Ma, Geng Liu, Ruiting Tong, and Xiaocai Zhang \\ School of Mechanical Engineering, Northwestern Polytechnical University, Xi'an 710072, China \\ Correspondence should be addressed to Geng Liu, npuliug@nwpu.edu.cn
}

Received 15 June 2012; Accepted 3 October 2012

Academic Editor: Slim Choura

Copyright (C) 2012 Shangjun Ma et al. This is an open access article distributed under the Creative Commons Attribution License, which permits unrestricted use, distribution, and reproduction in any medium, provided the original work is properly cited.

As a more powerful transmission device, planetary roller screws (PRSs) recently have received more attention, compared to conventional ball screws. However, due to the complicated and unclear relationships among the PRS components' parameters, it is difficult to design high-quality PRSs. To facilitate the PRS design, a new study on the parameter relationships of PRS is conducted in this work. New models of the axial stiffness and the frictional moment of PRS are developed, and the relationships of the axial stiffness and the frictional moment in terms of contact angle, helical angle, and tooth number of the roller thread are investigated. This study could contribute to the research of PRS to improve its transmission performance, especially to increase its positioning accuracy.

\section{Introduction}

Planetary roller screws (PRSs) are mechanical transmission devices for motion conversion between rotary and linear. A PRS mainly consists of a nut, a screw, and a group of rollers. The nut includes two planetary carriers and two ring gears on both ends to locate and guide the rollers. Each roller has a single-start thread with convex flank and a number of teeth at the ends. While the screw is rotating and the nut is moving, the nut and the rollers slide along axial direction of the screw. Meanwhile, the rollers rotate and engage with the screw and the nut, simultaneously. Compared to conventional ball screws, PRS has the following advantages: (1) PRS can take larger loads, (2) PRS has better kinematics and dynamics, (3) in working condition, PRS generates less vibration and lower noise, (4) PRS can work in much tougher condition, and (5) the transmission precision of PRS is higher. Due to these advantages, much research on PRS has been carried out, and the PRSs have been used in the medical, aerospace, and machine tools industries. 
Earlier work on PRS has included research on the efficiency and failure modes [1], dynamical load testing [2], a calculation method for the static stiffness of PRS [3], and a study on the effects of wet and dry lubrications under oscillatory motion [4]. In recent years, Tselishchev and Zharov [5] provided a calculation method for an elastic element operating at large displacements with a distributed load. This method could be used to select the static and dynamic characteristics of PRS mechanisms. Velinsky et al. [6] used the concept of orbital mechanics to analyze the kinematics and the efficiency of PRS. The paper showed that though slip must occur between the rollers and the screw of PRS, the overall lead of the mechanism was independent of this slip. Hojjat and Mahdi Agheli [7] analyzed the capabilities and limitations of PRS and showed that large leads and extremely small leads were easily obtainable. The slip phenomenon had been studied regarding the forces acting on the roller during the rotation of screw. Jones and Velinsky [8] extended the kinematics model of [6] and provided a fundamental research of the nut-roller contact slip tendency of PRS and the associated axial migration of the roller relative to the nut. Jones and Velinsky [9] furthermore used the principle of conjugate surfaces to establish a contact kinematical model at the screw-roller and nut-roller interfaces. In addition, optimal design of PRS for thread clearance and gear parameters was discussed in [10-12]. An axial stiffness model considering load distribution of PRS was established [13] and stress distribution of roller thread was also obtained [14]. However, the relationships and constraints among the PRS components are complicated, and some of them are unclear. Up to now, few research works on the parameter relationships of PRS have been conducted in order to design high-quality PRSs. The relationships of the axial stiffness and the frictional moment in terms of the PRS components' parameters were seldom mentioned in the published articles.

To address the above mentioned problems and facilitate the PRS design, a new and comprehensive study on the relationships of the axial stiffness and the frictional moment in terms of the PRS components' parameters is conducted in this work. First, the structure and the mechanism of PRS are introduced. Second, the necessary conditions and the relationships among the PRS components' parameters are provided. Then, the models of the axial stiffness and the frictional moment of PRS are developed. Finally, the models are examined in detail to explicitly show the relationships of the axial stiffness and the frictional moment in terms of the PRS parameters.

\section{Mechanism of the PRS}

\subsection{The PRS Structure}

Basically, PRSs are classified into two types: standard PRS and inverted PRS. A standard PRS consists of a screw, a nut, and a group of rollers. The lack of axial movement of the roller relative to the nut and the gearing of rollers to nut, are definitive of the standard PRS. Similarly, an inverted PRS consists of a screw, a nut, and a group of rollers. The lack of axial movement of the roller relative to the screw, and the gearing of rollers to screw are definitive of the inverted PRS. This type of roller screw is developed simultaneously with the standard PRS. Since the standard PRS is more applicable in industry, this work is focused on the standard PRS, which is illustrated in Figure 1.

In this diagram, the screw $A$, a shaft with a multistart V-shaped thread, provides a helical raceway for the multiple rollers that are radially arrayed around it and encapsulated by a threaded nut $C$ with internal threads, which are complementary to that of the screw. 


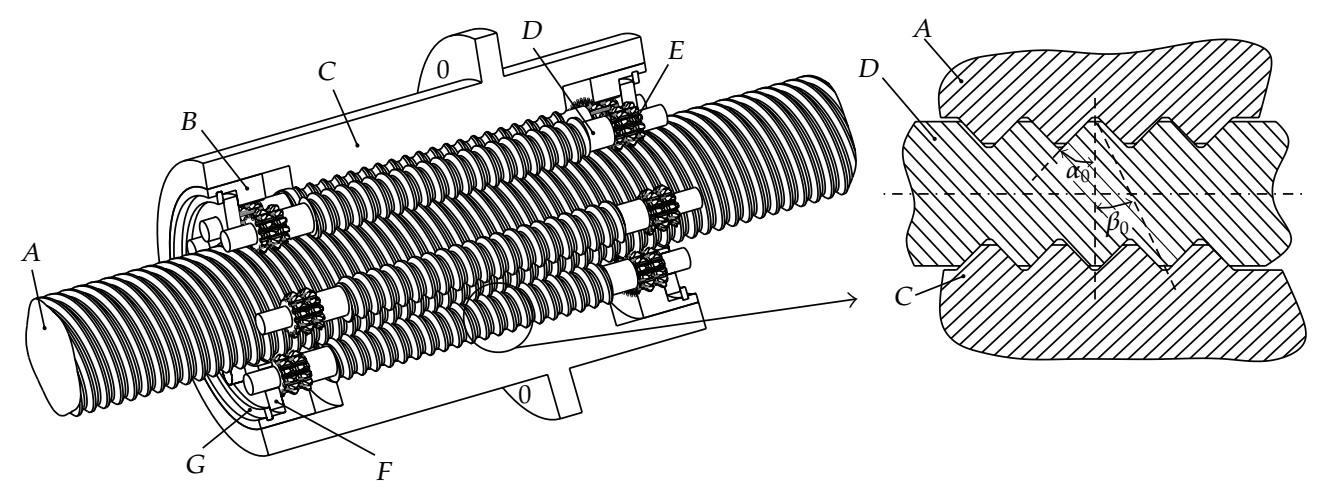

Figure 1: The image with the structure of PRS and a broken view of the screw $A$, the rollers $D$, and the nut C.

The rollers $D$ have a single-start thread with convex flanks which reduce the friction at the interfaces. The matched helix angle prevents axial movement between the nut and the rollers as the rollers spin. The nut assembly includes planetary carriers $F$ and ring gears $B$ that position and guide the rollers. The planetary carriers, which rotate within the ring gears, have equidistant holes that act as rotary bearings for the smooth pivot ends of the rollers. The ring gears time the spinning and orbit of the rollers about the screw axis by engaging gear teeth $E$ near the ends of the rollers. The planetary carriers rotate on axis with the screw in unison with the orbit of the rollers. The planetary carriers float relative to the nut, axially secured by the spring rings $G$, because they spin around the screw at a lower angular velocity than the nut. Besides, the parameters $\alpha_{0}$ and $\beta_{0}$ are the contact angle and the helix angle, respectively.

\subsection{Necessary Conditions of Parameter Design of PRS}

The operating mechanism of the components is analogous to the motion of a planetary gear train. While the rollers roll inside the nut, they create a virtual internal thread between the screw and the nut. The thread and the gear of roller are engaged with nut thread and ring gear synchronously. In order to realize the above movements, necessary conditions must be realized as follows.

\subsubsection{Pure Rolling between the Nut and the Roller}

Based on the principle of a planetary gear train, the relationship between the angular velocities can be described in the following equations [15]:

$$
\begin{gathered}
\frac{\omega_{s}-\omega_{p 1}}{\omega_{r}-\omega_{p 1}}=-\frac{d_{n}}{d_{s}}, \\
\frac{\omega_{s}-\omega_{p 2}}{\omega_{r}-\omega_{p 2}}=-\frac{d_{r}}{d_{s}} \frac{Z_{n}}{Z_{r}},
\end{gathered}
$$

where $\omega_{s}$ and $\omega_{r}$ are the angular velocities of screw and the roller, respectively, and $\omega_{p 1}$ and $\omega_{p 2}$ are the angular velocities of the planetary carriers on the left side and right side. The tooth 
number of ring gears is denoted as $Z_{n}$, and the tooth number of gears near the ends of rollers is noted as $Z_{r}$. As mentioned earlier, $d_{n}, d_{r}$, and $d_{s}$ are the effective diameters of the nut, the roller, and the screw.

In order to ensure that the rollers have pure rolling inside the nut, the angular velocity of the planetary carrier on the left side must be equal to that of the planetary carrier on the right side, which can be written as

$$
\omega_{p 1}=\omega_{p 2}
$$

Substitute (2.1) into (2.2) yields

$$
\frac{Z_{n}}{Z_{r}}=\frac{d_{n}}{d_{r}} .
$$

Equation (2.3) indicates that the ratio of the tooth number must be equal to the ratio of effective diameters of the nut and the roller.

\subsubsection{No Relative Axial Movement between the Nut and the Roller}

In order to guarantee no relative axial movement between the nut and the roller, firstly the helix angle on the nut thread must be equal to that of the thread on the roller. Based on the relation of the movements, the linear velocity of the contact point between the roller and the screw is defined as $v$ as shown in Figure 2. Since the nut is fixed, the linear velocity of the contact point between the roller and the nut has to be zero. The linear and orbital speeds of the center of the roller, which rotate around the screw, are $v / 2$ and $\omega_{m}$, respectively. The relationship between the speeds is

$$
\frac{\omega_{s}}{\omega_{m}}=\frac{2 v / d_{s}}{(v / 2) /\left(d_{s} / 2+d_{r} / 2\right)}=\frac{2\left(d_{s}+d_{r}\right)}{d_{s}}
$$

The relative axial displacement, $l_{r n}$, between the nut and the roller is given as

$$
l_{r n}=\frac{\omega_{m}}{\omega_{s}} n_{n} p_{n}-\frac{\omega_{r}}{\omega_{s}} n_{r} p_{r}
$$

where $n_{n}$ and $n_{r}$ are the starts of the nut and the roller, respectively, and $p_{n}$ and $p_{r}$ denote the pitches of the nut and the roller, respectively. Generally $n_{r}=1$ and $p_{n}=p_{r}=p$, and (2.5) can be then rewritten as

$$
l_{r n}=\frac{\omega_{m}}{\omega_{s}} n_{n} p-\frac{\omega_{r}}{\omega_{s}} p
$$

For the case without relative axial displacement between the nut and the roller, $l_{r n}=0$, combining (2.6), the starts of the nut can be written as

$$
n_{n}=\frac{d_{s}+2 d_{r}}{d_{r}}=\frac{d_{n}}{d_{r}}
$$


The relative axial displacement, $l_{r s}$, between the screw and the roller is obtained by adding the axial displacements from the roller spinning, rotations around the screw, and the leads of the screw together, yielding

$$
l_{r s}=\frac{\omega_{r}}{\omega_{s}} n_{r} p_{r}-\frac{\omega_{m}}{\omega_{s}} n_{s} p_{s}+n_{s} p_{s}
$$

As noted earlier, (2.8) can be rearranged as

$$
l_{r s}=\frac{\omega_{r}}{\omega_{s}} p-\frac{\omega_{m}}{\omega_{s}} n_{s} p+n_{s} p
$$

When the roller rolls on the screw with no slip; that is, $l_{r s}$ is an absolute constant, (2.9) is simplified consequently as

$$
\frac{\omega_{r}}{\omega_{s}} p-\frac{\omega_{m}}{\omega_{s}} n_{s} p=0
$$

Then, (2.10) can be expressed as

$$
n_{s}=\frac{\omega_{r}}{\omega_{m}}=\frac{d_{n}}{d_{r}}
$$

From (2.7) and (2.11), the following equation can be derived:

$$
n_{s}=n_{n}
$$

\subsubsection{Condition of Concentricity}

Since the rollers rotate around the screw with planetary motion, the rollers are concentric with screw and nut. The distance between the centers of the roller and the nut can be calculated as

$$
a_{r n}=\frac{\left(d_{n}-d_{r}\right)}{2}
$$

The center distance between the roller and the screw can be written as

$$
a_{r s}=\frac{\left(d_{s}+d_{r}\right)}{2}
$$

For $a_{r n}=a_{r s}$, combining with (2.3), (2.7), and (2.11), the condition of concentricity can be represented as

$$
\frac{d_{s}}{d_{r}}=\frac{Z_{n}}{Z_{r}}-2=n_{s}-2=n_{n}-2
$$




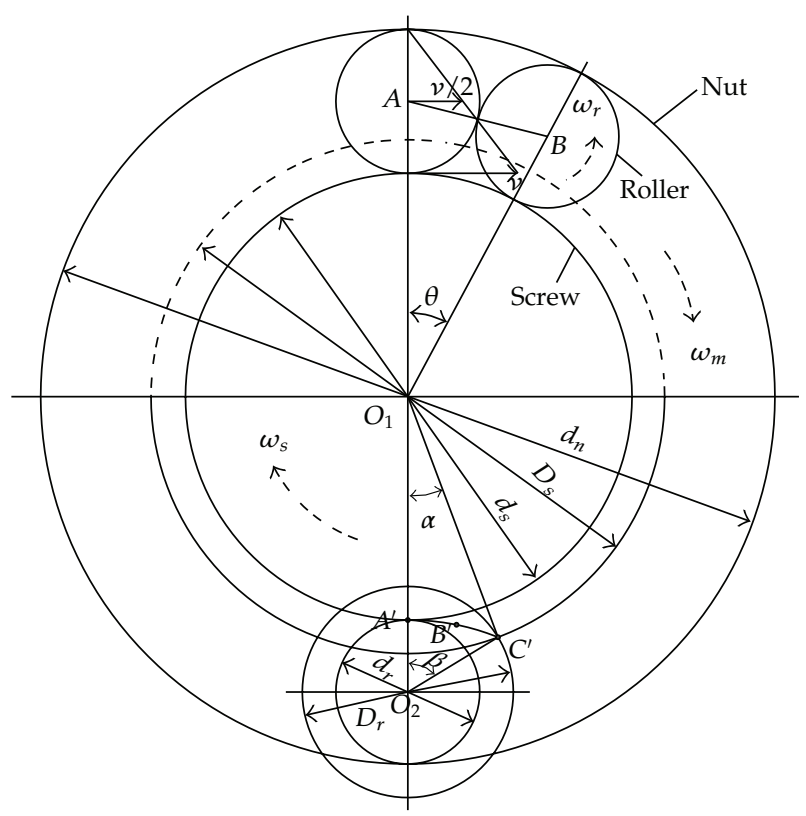

Figure 2: Angular position and parameters of PRS.

\subsubsection{Spaced Distribution of Rollers}

The rollers are located symmetrically around the screw. It is necessary to retain a certain distance between two consecutive rollers. So the angle between two consecutive rollers can be defined as $\theta=360^{\circ} / N_{0}$. In $\triangle A O_{1} B$ as shown in Figure 2, the relationship can be stated as

$$
\sin \frac{\theta}{2}=\frac{\overline{A B} / 2}{\left(d_{r} / 2+d_{s} / 2\right)}
$$

where $N_{0}$ is the number of rollers. In Figure 2, $D_{r}$ denotes the external diameter of the roller. With $\overline{A B}>D_{r}$, the relationship between the center distance of two consecutive rollers and external diameter of the roller is described as

$$
\left(d_{r}+d_{s}\right) \sin \left(\frac{180^{\circ}}{N_{0}}\right)>D_{r}
$$

The maximum number of rollers can be obtained from (2.17) as

$$
N_{0}<\frac{180^{\circ}}{\arcsin \left(D_{r} /\left(d_{r}+d_{s}\right)\right)}
$$

\subsubsection{Noninterference between Roller and Screw Threads}

In PRS, since the roller's helix angle is the same as that of the nut, no interference can occur. However, the interference problem has to be considered between the roller and the screw 
[16]. The contact point between the roller and the screw is defined as $A^{\prime}$ in Figure 2, the intersection point between external diameter of the screw and external diameter of the roller as $C^{\prime}$, and an arbitrariness point between point $A^{\prime}$ and point $C^{\prime}$ as $B^{\prime}$. When contact point is at point $C^{\prime}$; the maximum axial displacement $p / 2$ is reached between the helix lines of the roller and the screw. Therefore, the problem of interference of helix line may present at point $C^{\prime}$, the condition of noninterference needs to be analyzed between the roller and the screw.

By using the Law of Cosines in $\Delta \mathrm{O}_{1} \mathrm{O}_{2} \mathrm{C}^{\prime}$, as shown in Figure 2, one may get

$$
\overline{O_{2} C^{\prime 2}}=\overline{O_{1} O_{2}^{2}}+\overline{O_{1} C^{\prime 2}}-2 \overline{O_{1} O_{2}} \overline{O_{1} C^{\prime}} \cos \alpha,
$$

where $\alpha$ is the phase angle between the two consecutive screw threads.

Substituting $D_{s}$ and $D_{r}$ into (2.19) gives

$$
\left(\frac{D_{r}}{2}\right)^{2}=\left(\frac{d_{r}+d_{s}}{2}\right)^{2}+\left(\frac{D_{s}}{2}\right)^{2}-2\left(\frac{d_{r}+d_{s}}{2}\right) \frac{D_{s}}{2} \cos \alpha
$$

The angle of $\alpha$ in Figure 2 can be expressed as

$$
\alpha=\arccos \left[\frac{D_{s}^{2}-D_{r}^{2}+\left(d_{r}+d_{s}\right)^{2}}{2 D_{s}\left(d_{r}+d_{s}\right)}\right]
$$

Similarly, we have $\overline{O_{1} C^{\prime 2}}=\overline{O_{1} O_{2}^{2}}+\overline{O_{2} C^{\prime 2}}-2 \overline{O_{1} O_{2}} \overline{O_{2} C^{\prime}} \cos \beta$,

$$
\begin{gathered}
\left(\frac{D_{s}}{2}\right)^{2}=\left(\frac{d_{r}+d_{s}}{2}\right)^{2}+\left(\frac{D_{r}}{2}\right)^{2}-2\left(\frac{d_{r}+d_{s}}{2}\right) \frac{D_{r}}{2} \cos \beta, \\
\beta=\arccos \left[\frac{D_{r}^{2}-D_{s}^{2}+\left(d_{r}+d_{s}\right)^{2}}{2 D_{r}\left(d_{r}+d_{s}\right)}\right]
\end{gathered}
$$

where $\beta$ is the phase angle between the two consecutive roller threads.

In practice, when the phase angle between the two consecutive screw threads is $\alpha$, the axial displacement between them can be written as

$$
l_{s}=\frac{n_{s} p \alpha}{360^{\circ}}
$$

Similarly,

$$
l_{r}=\frac{n_{r} p \beta}{360^{\circ}}
$$

If the hands of the screw threads are the same as that of the roller thread, the directions of $l_{s}$ and $l_{r}$ are opposite. Therefore, no interference happens when condition $l_{s}+l_{r}<p / 2$ is satisfied. Substituting (2.23) and (2.24) to the condition leads to

$$
n_{s} \alpha+\beta<180^{\circ} \text {. }
$$


When the direction of $l_{s}$ is the same as that of $l_{r}$, then the condition without the problem of interference is $l_{s}-l_{r}<p / 2$, and we have

$$
n_{s} \alpha-\beta<180^{\circ}
$$

From the above analysis, the condition of engagement between the rollers and the screw is that the hand and helix angle should fulfill the requirements given in (2.25) and (2.26). Besides, the pitch of screw has to be equal to that of the roller, whereas the hand and helix angle may be different.

\subsubsection{Relationship between the Number of Rollers and the Number of the Starts}

Assuming that the lead of nut is equal to $n_{n} p$, the axial displacement of nut, $l_{n}$, is then equal to $n_{n} p / N_{0}$. The axial displacement of the thread at the engagement points of two consecutive rollers and the screw is also equal to $l_{n}$. Rollers and screw can engage normally only when the distribution of the screw thread with the $360^{\circ} / N_{0}$ is the same as that of two consecutive rollers at the engagement points. The $l_{n}$ can be chosen as the following three numbers:

(i) $l_{n}=p\left(n_{n}=N_{0}\right)$; that is, the starts of the nut are equal to the number of rollers. For this case, all rollers have no relative axial displacement. As a result, when the discrepancy of the screw thread is $360^{\circ} / N_{0}$, they can only engage normally with the axial displacement being integer times of $p$. Therefore, the relationship between the number of rollers and the starts would be described as

$$
n_{s}=C N_{0}=C n_{n}
$$

with $C$ a positive integer.

(ii) $l_{n}<p\left(n_{n}<N_{0}\right)$; that is, the starts of the nuts are less than the number of rollers. When the discrepancy of the screw thread is $360^{\circ} / N_{0}$ and with the screw, the rollers and the nut having the same hand, the axial displacement of screw is $n_{s} p / N_{0}=$ $(C-1) p+n_{n} p / N_{0}$. Accordingly, the relationship between the number of rollers and the starts is

$$
n_{s}=(C-1) N_{0}+n_{n}
$$

If the hand of screw is opposite to that of rollers and nut, the axial displacement of screw is $n_{s} p / N_{0}=C p-n_{n} p / N_{0}$. Similarly, the relationship between the number of rollers and the starts is written as

$$
n_{s}=C N_{0}-n_{n}
$$

(iii) $p<l_{n}<2 p\left(N_{0}<n_{n}<2 N_{0}\right)$. When the discrepancy of the screw thread is $360^{\circ} / N_{0}$ and the hands of the screw, the rollers, and the nut are identical, 
the axial displacement of screw is $n_{s} p / N_{0}=(C-1) p-p+n_{n} p / N_{0}$. Likewise, the relationship between the number of rollers and the starts is represented as

$$
n_{s}=(C-2) N_{0}+n_{n}
$$

If the hand of the screw is opposite to that of the rollers and the nut, the axial displacement of screw is $n_{s} p / N_{0}=(C+1) p-n_{n} p / N_{0}$. In the same way, the relationship between the number of the rollers and the starts is expressed as

$$
n_{s}=(C+1) N_{0}-n_{n}
$$

\subsubsection{Engagement Condition between Gear and Thread of the Roller}

The thread and the gear of the rollers engage with the nut thread and ring gears. In order to ensure that the rollers move in the screw grooves, we must follow the conventional standards of the gear design [17]. In addition, the tip diameter of gear should be less than the external diameter of the thread, indicating

$$
m_{g}\left(Z_{r}+2 h_{a}^{*}\right) \leq D_{r}
$$

where $m_{g}$ denotes the module of gear and $h_{a}^{*}$ the addendum modification of gear.

\subsubsection{Assemble Condition of Rollers}

During the assembling, it is required that all rollers are assembled in the nut in turn. Both the revolving angle and the spinning angle are limited with revolving angle to be $360^{\circ} / N_{0}$. And the spinning angle is

$$
\theta_{r}=\frac{n_{n}}{N_{0}} 360^{\circ}
$$

\section{Modeling of Axial Stiffness for PRS}

The axial stiffness is a dominating parameter for dynamic performance of PRS. It can be obtained by solving the axial elastic deformation. The normal load created on the contact surface of either the screw or the nut can cause an elastic deformation which is the total deformation of two solid surfaces under the Hertzian contact. Therefore, the total deformation of PRS is calculated by summing the Hertzian contact deformation, the contact deformation at two consecutive teeth of roller thread, and the axial deformation on teeth of screw thread and nut thread. 


\subsection{Hertzian Contact Deformation}

According to the Hertzian contact theory, the contact deformation, $\delta_{h}$, can be calculated as

$$
\delta_{h}=\frac{2 K(e)}{\pi m_{a}} \sqrt[3]{\frac{9}{32} E^{\prime 2} N^{2} \sum \rho},
$$

where $E^{\prime}$ is the effective Young's modulus, which can be explicitly shown as $E^{\prime}=\left(1-\mu_{s}^{2}\right) / E_{s}+$ $\left(1-\mu_{n}^{2}\right) / E_{n}$, with $\mu_{s}$ being the Poisson's ratio of the screw, $\mu_{n}$ the Poisson's ratio of the nut, $E_{s}$ and $E_{n}$ the Young's modulus of the screw and the nut, respectively, $e$ the eccentricity of contact ellipse, $K(e)$ the complete elliptic integral of the first kind, and $N$ the normal load. The dimensionless coefficients $m_{a}$ and $m_{b}$ are approximated as

$$
\begin{aligned}
& m_{a}=\sqrt[3]{\frac{2 L(e)}{\pi k^{2}}}, \\
& m_{b}=\sqrt[3]{\frac{2 L(e) k}{\pi}},
\end{aligned}
$$

where $L(e)$ is the complete elliptic integral of the second kind, and $k=b / a$ with $a$ and $b$ being the half lengths of the major and minor axis of the elliptical contact surface as

$$
\begin{aligned}
& a=m_{a} \sqrt[3]{\frac{3 N E^{\prime}}{2 \sum \rho}}, \\
& b=m_{b} \sqrt[3]{\frac{3 N E^{\prime}}{2 \sum \rho}},
\end{aligned}
$$

where $\sum \rho$ denotes the curvature sum.

The main curvature parameters, $\rho_{11}, \rho_{12}, \rho_{21}$, and $\rho_{22}$, are given dependently upon the calculations for the screw or the nut. In the screw raceway,

$$
\begin{aligned}
& \rho_{11}=\rho_{12}=\frac{1}{R}, \\
& \rho_{21}=0, \\
& \rho_{22}=\frac{2 \cos \alpha_{0}}{d_{m}-2 R \cos \alpha_{0}} .
\end{aligned}
$$




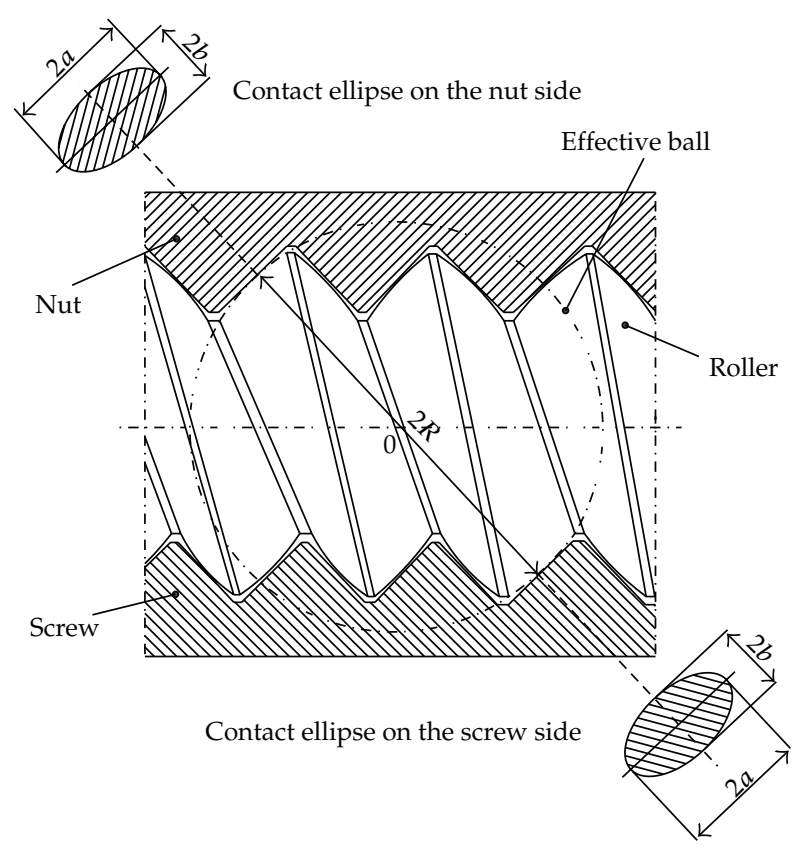

Figure 3: Effective ball and contact ellipse of PRS.

In the raceway of the nut

$$
\begin{aligned}
& \rho_{11}=\rho_{12}=\frac{1}{R^{\prime}} \\
& \rho_{21}=0, \\
& \rho_{22}=\frac{-2 \cos \alpha_{0}}{d_{m}+2 R \cos \alpha_{0}},
\end{aligned}
$$

where $R$ denotes the radius of effective ball, as shown in Figure 3, and can be written as

$$
R=\frac{d_{r}}{2 \sin \alpha_{0}}
$$

where $\alpha_{0}$ is the contact angle. $F(\rho)$ is expressed as a function of curvature

$$
F(\rho)=\frac{\left|\left(\rho_{11}-\rho_{12}\right)+\left(\rho_{21}-\rho_{22}\right)\right|}{\sum \rho}
$$

For a specific solution of $F(\rho)$, the parameters $m_{a}, m_{b}$, and $2 K(e) / \pi m_{a}$ can be then determined from the relationship of dimensionless contact parameters given in [18], which is listed Table 2 of the appendix. 
Table 1: List of the parameters used in the present study.

\begin{tabular}{lccc}
\hline Parameter & Symbol & Unit & Value \\
\hline Effective diameter of screw (right hand) & $d_{s}$ & $\mathrm{~mm}$ & 30 \\
Starts & $n_{s}=n_{n}$ & & 5 \\
Pitch & $p$ & $\mathrm{~mm}$ & 2 \\
Helix angle & $\beta_{0}$ & $\circ$ & 6.056 \\
Contact angle & $\alpha_{0}$ & $\circ$ & 45 \\
Effective diameter of roller (right hand) & $d_{r}$ & $\mathrm{~mm}$ & 10 \\
Effective diameter of nut (right hand) & $d_{n}$ & $\mathrm{~mm}$ & 50 \\
External diameter of nut thread & $D_{n}$ & $\mathrm{~mm}$ & 51.2 \\
Tooth number of the roller thread & $\tau$ & & 20 \\
Number of rollers & $N_{0}$ & & 10 \\
Orbital diameter of roller & $d_{m}$ & $\mathrm{~mm}$ & 40 \\
Radius of effective ball & $R$ & $\mathrm{~mm}$ & 7.0711 \\
Rolling coefficient of friction & $f_{g}$ & & 0.005 \\
Sliding coefficient of friction & $f_{h}$ & & 0.05 \\
Loss coefficient of energy & $\gamma$ & & 0.007 \\
Young's modulus & $E_{s}, E_{n}$ & Pa & $210 \times 10^{9}$ \\
Poisson's ratio & $\mu_{s}, \mu_{n}$ & & 0.3 \\
\hline
\end{tabular}

Table 2: Dimensionless contact parameters [18].

\begin{tabular}{lccc}
\hline$F(\rho)$ & $m_{a}$ & $m_{b}$ & $2 K(e) / \pi m_{a}$ \\
\hline 0 & 1 & 1 & 1 \\
0.1075 & 1.0760 & 0.9318 & 0.9974 \\
0.3204 & 1.2623 & 0.8114 & 0.9761 \\
0.4795 & 1.4556 & 0.7278 & 0.9429 \\
0.5916 & 1.6440 & 0.6687 & 0.9077 \\
0.6716 & 1.8258 & 0.6245 & 0.8733 \\
0.7332 & 2.011 & 0.5881 & 0.8394 \\
0.7948 & 2.265 & 0.5480 & 0.7961 \\
0.83495 & 2.494 & 0.5186 & 0.7602 \\
0.87366 & 2.800 & 0.4863 & 0.7169 \\
0.90999 & 3.233 & 0.4499 & 0.6636 \\
0.93657 & 3.738 & 0.4166 & 0.6112 \\
0.95738 & 4.395 & 0.3830 & 0.5551 \\
0.97290 & 5.267 & 0.3490 & 0.4960 \\
0.983797 & 6.448 & 0.3150 & 0.4352 \\
0.990902 & 8.062 & 0.2814 & 0.3745 \\
0.995112 & 10.222 & 0.2497 & 0.3176 \\
0.997300 & 12.789 & 0.2232 & 0.2705 \\
0.9981847 & 14.839 & 0.2072 & 0.2427 \\
0.9989156 & 17.974 & 0.18822 & 0.2106 \\
0.9994785 & 23.55 & 0.16442 & 0.17167 \\
0.9998527 & 37.38 & 0.13050 & 0.11995 \\
1 & $\infty$ & 0 & 0 \\
\hline
\end{tabular}


The contact area is an ellipse and the deformations are calculated by (3.9) and (3.10). In the screw raceway

$$
\delta_{s}=f_{s} N_{i}^{2 / 3} \quad(i=1,2,3, \ldots, \tau)
$$

and in the raceway of the nut

$$
\delta_{n}=f_{n} N_{i}^{2 / 3} \quad(i=1,2,3, \ldots, \tau),
$$

where $\tau$ denotes the tooth number of roller thread, and $f_{s}$ and $f_{n}$ are defined to be the elastic modulus of elliptical contact points of the screw and the nut, respectively. So we can get

$$
\begin{aligned}
& f_{s}=\left(\frac{2 K(e)}{\pi m_{a}} \sqrt[3]{\frac{9 E^{\prime 2} \sum \rho}{8}}\right)_{s} \\
& f_{n}=\left(\frac{2 K(e)}{\pi m_{a}} \sqrt[3]{\frac{9 E^{12} \sum \rho}{8}}\right)_{n} .
\end{aligned}
$$

The Hertzian contact deformation component in the axial direction yields

$$
\delta_{h}=\frac{\left(\delta_{s}+\delta_{n}\right)}{\sin \alpha_{0} \cos \beta_{0}}
$$

where $\beta_{0}$ is the helix angle as shown in Figure 1, which satisfies

$$
\tan \beta_{0}=\frac{n_{s} p}{\pi d_{s}}
$$

The following load distribution expression can be obtained from literature [19]:

$$
F_{i-1}^{2 / 3}=F_{i}^{2 / 3}+\left(\frac{1}{E_{s} A_{s}}+\frac{1}{E_{n} A_{n}}\right) \frac{N_{0} p}{4\left(f_{s}+f_{n}\right)} \sum_{j=1}^{\tau} F_{j} \sin ^{2} \alpha_{0} \cos ^{2} \beta_{0}
$$

where $F$ denotes the axial load, $A_{s}$ and $A_{n}$ are the effective cross-section areas of the screw and the nut, respectively, which can be derived as

$$
\begin{gathered}
A_{s}=\frac{\pi d_{s}^{2}}{4}, \\
A_{n}=\frac{\pi\left(D_{n}^{2}-d_{n}^{2}\right)}{4},
\end{gathered}
$$


with $D_{n}$ and $d_{n}$ being the external diameter and effective diameter of the nut. It is assumed that the load distribution of screw is the same as that of the nut. So the relationship between axial load and normal load is written as

$$
F_{i}=N_{i} \sin \alpha_{0} \cos \beta_{0}
$$

The above equations can be used to achieve the axial contact deformation of the nut

$$
\delta_{h}=\frac{\left(f_{s}+f_{n}\right) N_{\tau}^{2 / 3}}{\sin \alpha_{0} \cos \beta_{0}}
$$

where $N_{\tau}$ is the normal load of the $\tau$ th tooth of roller thread.

\subsection{Axial Deformation of the Two Consecutive Teeth of the Roller Thread}

The axial tension $F_{s r}$ of the screw and the axial compression $F_{n r}$ of the nut are acting on the rollers from the operating conditions. In the screw raceway, the axial deformation of half pitch from $(m-1)$ th thread tooth to $m$ th thread tooth is expressed as

$$
\delta_{s r(m-1, m)}=\frac{F_{s r} p}{E_{S} A_{s}} .
$$

In the raceway of the nut

$$
\delta_{n r(m-1, m)}=\frac{F_{n r} p}{E_{n} A_{n}} .
$$

The total axial deformation of the two consecutive teeth of the roller thread can be stated as

$$
\delta_{r}=\delta_{s r(m-1, m)}+\delta_{n r(m-1, m)}=\left(\frac{1}{E_{s} A_{s}}+\frac{1}{E_{n} A_{n}}\right) \frac{N_{0} p}{4} \sum_{j=1}^{\tau} N_{j} \sin \alpha_{0} \cos \beta_{0} .
$$

\subsection{Axial Deformation on Teeth of the Screw Thread and the Nut Thread}

There are six types of elastic deformations generated due to the normal load $N_{i}$ acting on the $i$ th thread tooth as follows [20]: the bending deformation $\delta_{1}$, the deformation $\delta_{2}$ from shear force, the deformation $\delta_{3}$ of the thread tooth from the inclination moment, the shear deformation of thread tooth root $\delta_{4}$, the deformation $\delta_{5}$ of the screw thread tooth from radial 
shrinkage, and the deformation $\delta_{6}$ of the nut thread tooth from radial expansion. They are expressed as

$$
\begin{aligned}
& \delta_{1}=\left(1-\mu_{x}^{2}\right) \frac{3 N_{\tau} \cos \alpha_{0} \cos \beta_{0}}{4 E_{x} \pi d_{x}}\left(2 \ln 2-\frac{3}{2}\right), \\
& \delta_{2}=\left(1+\mu_{x}\right) \frac{6 N_{\tau} \cos \alpha_{0} \cos \beta_{0}}{5 E_{x} \pi d_{x}}, \\
& \delta_{3}=\left(1-\mu_{x}^{2}\right) \frac{3 N_{\tau} \cos \alpha_{0} \cos \beta_{0}}{8 E_{x} \pi^{2} d_{x}}, \\
& \delta_{4}=\left(1-\mu_{x}^{2}\right) \frac{3 N_{\tau} \ln 3 \cos \alpha_{0} \cos \beta_{0}}{E_{x} \pi^{2} d_{x}}, \\
& \delta_{5}=\left(1-\mu_{x}\right) \frac{N_{\tau} \cos \alpha_{0} \cos \beta_{0}}{2 \pi E_{x} p}, \\
& \delta_{6}=\left(\frac{D_{n}^{2}+d_{n}^{2}}{D_{n}^{2}-d_{n}^{2}}+\mu_{x}\right) \frac{N_{\tau} \cos \alpha_{0} \cos \beta_{0}}{2 \pi E_{x} p} .
\end{aligned}
$$

The subscript $x$ denotes the associated components as $s$ and $n$ for the screw and the nut, respectively. The total axial deformation of the screw is the summation of five components

$$
\delta_{s}^{\prime}=\delta_{1}+\delta_{2}+\delta_{3}+\delta_{4}+\delta_{5}
$$

The total axial deformation of the nut is

$$
\delta_{n}^{\prime}=\delta_{1}+\delta_{2}+\delta_{3}+\delta_{4}+\delta_{6}
$$

and the total axial deformation, $\delta$, of PRS is obtained by summing the Hertzian contact deformation, the axial deformation of the two consecutive teeth of the roller thread, and the axial deformation on teeth of the screw thread and the nut thread as follows:

$$
\delta=\delta_{h}+\delta_{r}+\left(\delta_{s}^{\prime}+\delta_{n}^{\prime}\right)
$$

\section{Modeling of Frictional Moment for PRS}

In this study, the frictional moment caused by elastic hysteresis and roller's spinning sliding is studied in detail.

\subsection{Frictional Moment Caused by Elastic Hysteresis}

As shown in Figure 3, the rollers in a PRS are mainly subjected to the loads perpendicular to the tangent plane at each contact surface [21]. Because of these normal loads, the rolling elements and raceways are brought into contact. 
As a rolling element under compressive load travels over a raceway, the material in front of the contact direction undergoes compression while the material in the rear of the contact is released. Based on the Hertzian contact theory, the work done by the compressive stress when the rolling element moves forward unit distance along the half lengths of the minor axis of the elliptical contact zone can be stated as

$$
W=\frac{3 b B N}{8}
$$

where

$$
B=\frac{\left(\rho_{11}+\rho_{12}\right)}{4}+\left(\rho_{21}+\rho_{22}\right)-\left[\left(\rho_{11}-\rho_{12}\right)^{2}+\left(\rho_{21}-\rho_{22}\right)^{2}+2\left(\rho_{11}-\rho_{12}\right)\left(\rho_{21}-\rho_{22}\right) \cos 2 \alpha_{0}\right]^{1 / 2}
$$

Since the energy loss is generated by elastic hysteresis in the rear of the contact area, the rolling frictional moment developed can be expressed as

$$
M_{f}=f_{g} N
$$

where $f_{g}=\gamma W / N, f_{g}$ is rolling coefficient of friction and $\gamma$ is loss coefficient of energy. Hence

$$
M_{f}=\frac{3 \gamma b B N}{8} .
$$

The frictional moment caused by elastic hysteresis on the screw side or nut side is equal to the sum of frictional moment on each roller. And the frictional moment of one roller can be calculated by the sum of all teeth moment components if the solutions of $b$ and $B$ are available. From (3.4) and (4.4), the frictional moment due to elastic hysteresis can be written as follows.

In the screw raceway,

$$
M_{f s}=N_{0} \sum_{i=1}^{\tau} \frac{3}{8} \gamma B_{s} m_{b s} \sqrt[3]{\frac{3 E_{s}^{\prime}}{2 \sum \rho_{s}}} N_{i}^{4 / 3}
$$

And in the raceway of the nut,

$$
M_{f n}=N_{0} \sum_{i=1}^{\tau} \frac{3}{8} \gamma B_{n} m_{b n} \sqrt[3]{\frac{3 E_{n}^{\prime}}{2 \sum \rho_{s}}} N_{i}^{4 / 3}
$$

\subsection{Frictional Moment Caused by the Spinning Sliding}

From the load distribution and contact area distribution on teeth of the roller thread, the frictional moment of differential area can be determined and the sliding friction force acts on origin of contact ellipse. Thus, the frictional moment caused by the spinning sliding on 
the screw side or nut side is equal to the sum of frictional moment on each roller. And the frictional moment of one roller can be calculated by the sum of all teeth moment components.

In the screw raceway, the component of sliding frictional moment in the axial direction is calculated by integrating over the contact area from $-a_{s i}\left(1-y^{2} / b_{s i}^{2}\right)^{1 / 2}$ to $a_{s i}\left(1-y^{2} / b_{s i}^{2}\right)^{1 / 2}$ and from 0 to $b_{s i}$. Accordingly, this component can be expressed as

$$
M_{k s}=N_{0} \cos \alpha_{0} \sum_{i=1}^{\tau} \iint f_{h} \frac{3 N_{i}}{2 \pi a_{s i} b_{s i}} \sigma_{i} p_{0} d x d y \quad(i=1,2,3 \ldots, \tau)
$$

Similarly, in the raceway of the nut,

$$
M_{k n}=N_{0} \cos \alpha_{0} \sum_{i=1}^{\tau} \iint f_{h} \frac{3 N_{i}}{2 \pi a_{n i} b_{n i}} v_{i} p_{0} d x d y \quad(i=1,2,3 \ldots, \tau),
$$

where $\sigma_{i}=\left(1-x^{2} / a_{s i}^{2}-y^{2} / b_{s i}^{2}\right), p_{0}=\left(x^{2}+y^{2}\right)^{1 / 2}$, and $v_{i}=\left(1-x^{2} / a_{n i}^{2}-y^{2} / b_{n i}^{2}\right),(i=$ $1,2,3 \ldots, \tau)$. The component of sliding frictional moment is calculated by integrating over the contact area from $-a_{n i}\left(1-y^{2} / b_{n i}^{2}\right)^{1 / 2}$ to $a_{n i}\left(1-y^{2} / b_{n i}^{2}\right)^{1 / 2}$ and from 0 to $b_{n i}$ with the sliding coefficient of friction, $f_{h}$.

The total frictional moment of PRS is the sum of moment components between the screw side and the nut side,

$$
M=M_{s}+M_{n}=M_{f s}+M_{k s}+M_{f n}+M_{k n}
$$

\section{Results and Discussion}

\subsection{Load Distribution on Teeth of the Roller Thread}

By using (3.9) to (3.16) and the parameters from Table 1, the load distribution on teeth of the roller thread can be achieved from numerical solutions. As shown in Figure 4, the load distribution on all twenty teeth of the roller thread obviously increases by increasing the axial loads. The axial load acting on the first tooth of roller thread is generally higher than that of other teeth because the first thread tooth is most close to the gear of roller as the diameter of root circle of the gear is smaller than inner diameter of roller thread. The relationship between the load distribution of the roller thread and the axial load has a similar tendency with that provided in [19]. Besides, it can be also seen from Figure 4 that the load distribution of the roller thread becomes worse as the axial load increases.

\subsection{Total Elastic Deformation in Axial Direction}

The total axial elastic deformation increases with the increase of the axial load as shown in Figure 5. Without preload, and when an axial load is lower than 2,000 N, the total axial elastic deformation increases rapidly because of fewer contact points among the screw, the roller, and the nut. The increase of deformation obviously slows down when the axial load is over $2,000 \mathrm{~N}$. The preload can be added to promote the entire stiffness. It is found that among all deformations defined in (3.25), the Hertzian contact deformation, $\delta_{h}$, contributes 


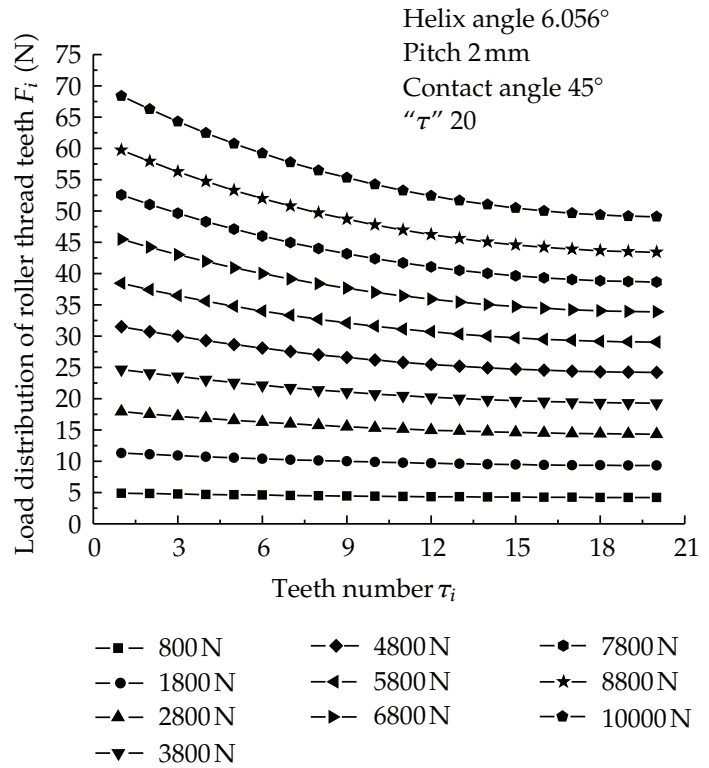

Figure 4: The load distribution on teeth of the roller thread.

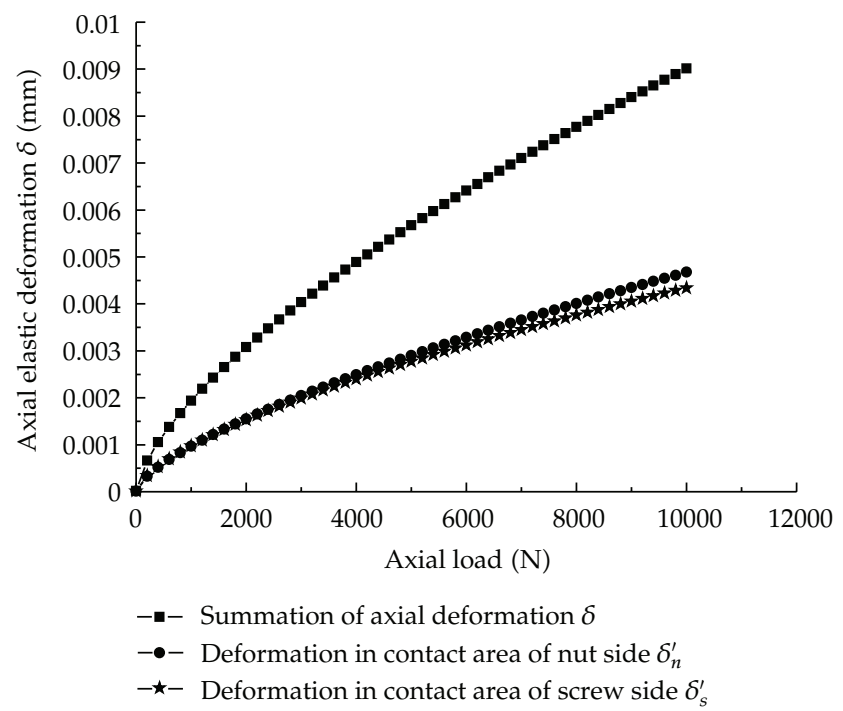

Figure 5: The relationship between axial load and axial elastic deformation.

the majority of the axial elastic deformation. It can be observed from Figure 5 that the elastic deformation on nut side is larger than screw side, which is mainly because the radial expansion deformation of nut threads, $\delta_{6}$, is larger than the radial shrinkage deformation of screw threads, $\delta_{5}$. 


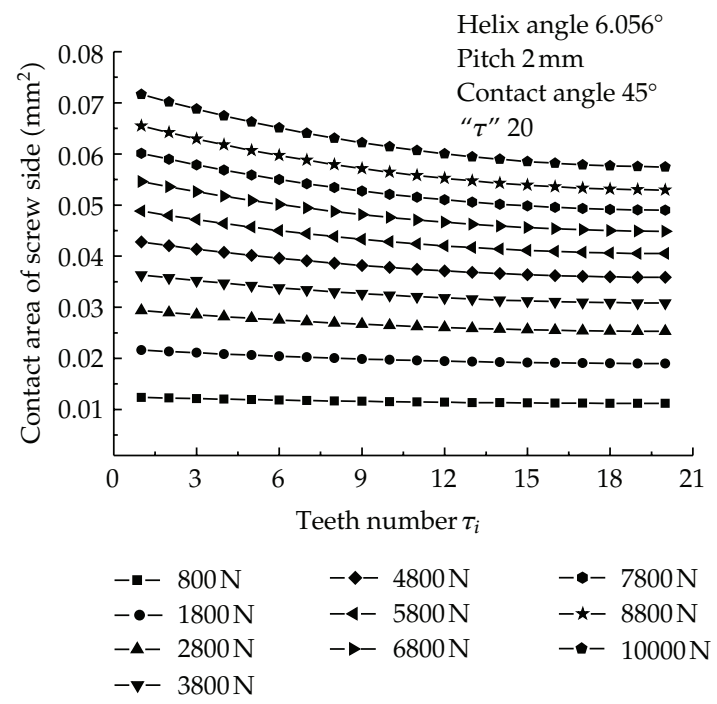

Figure 6: The contact area distribution on teeth of the roller thread on screw side.

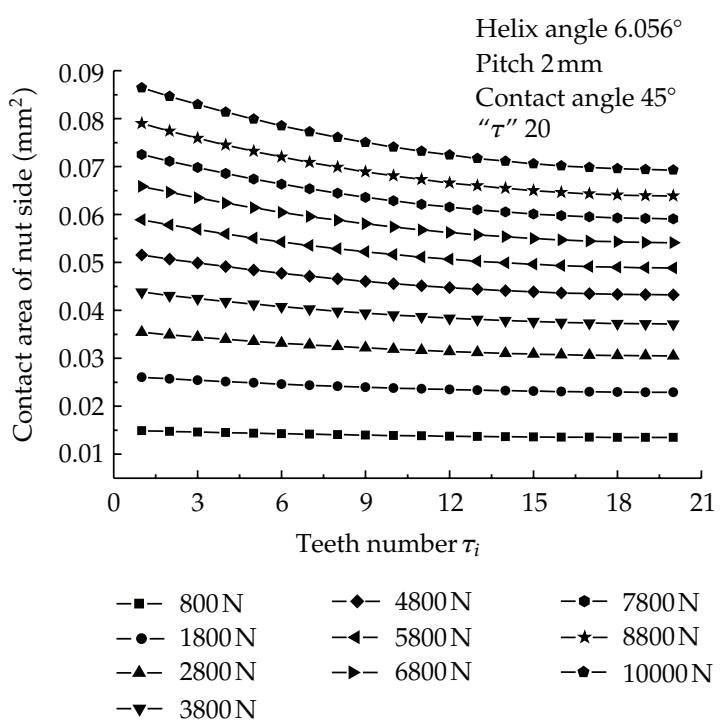

Figure 7: The contact area distribution on teeth of roller thread on nut side.

\subsection{Relationship between the Contact Area on Teeth of the Roller Thread and Axial Load}

The load is distributed on teeth of the roller thread and the contact area is directly influenced by the frictional moment. To enhance PRS's transmission efficiency, the distribution of contact area on teeth of the roller thread should be analyzed. The distribution and variation of contact areas on both screw side and nut side are almost the same trend as shown in Figures 6 and 7. When the axial load is less than $5,000 \mathrm{~N}$, the contact area has no obvious variation. When axial load is equal to $10,000 \mathrm{~N}$, the difference of contact areas between the first tooth and 


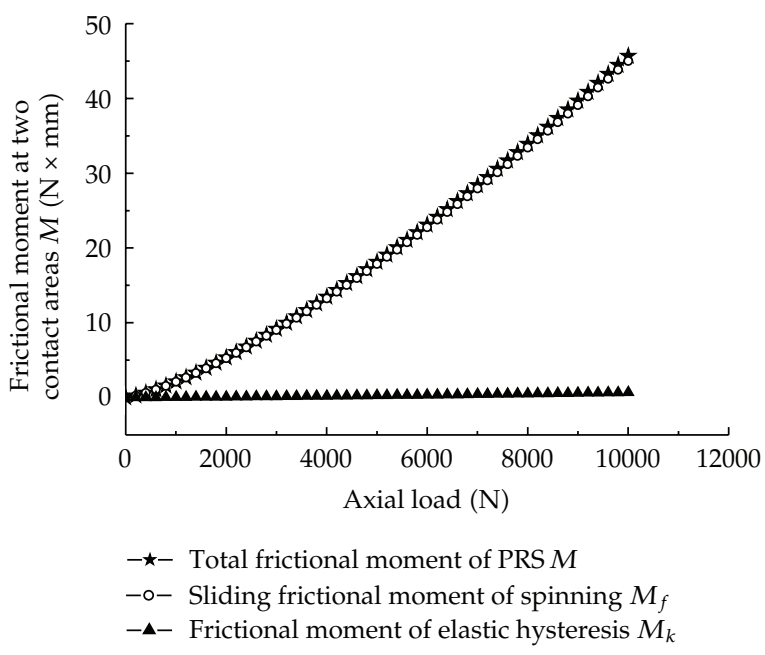

Figure 8: The relationship between the frictional moment and the axial load.

the 20th tooth on screw thread side is $0.0142 \mathrm{~mm}^{2}$, and on nut thread side the difference is $0.0171 \mathrm{~mm}^{2}$. It is thus clear that in spite of the increase of axial load, the contact area on screw side has gentle change, and the variation on nut side is always greater than that on screw side.

\subsection{Relationship between the Frictional Moment and the Axial Load}

The analysis of the relationship between the frictional moment and the axial load indicates that the elastic hysteresis gives little rise to friction and thus can be ignored as given in Figure 8 . The frictional moment is generated principally by roller's spinning sliding because the roller's spinning axis is always parallel to the axis of screw, and a contact angle $\alpha_{0}$ is formed between the pressure direction and the axis direction of screw. Therefore, the spinning axis of the roller is restricted and results shown in Figure 8 express that for any motion of PRS sliding always occurs.

As shown in Figure 8, the frictional moment caused by spinning sliding during movement is the greatest. The frictional moment increases with the increase of the axial load. It can be seen from Figure 8 that when the axial load is larger than $4,000 \mathrm{~N}$, an approximately linear relation appears between the frictional moment and the axial load.

\subsection{Influence of Contact Angle on Normal Load and Total Axial Elastic Deformation}

The normal load created on the contact surface of either the screw or the nut can cause an axial elastic deformation. This elastic deformation denotes the total axial elastic deformation of two solid surfaces under the Hertzian contact. The axial elastic deformation created at contact point of either the screw or the nut and the variation of the normal load distribution under various contact angles are shown in Figures 9 and 10, respectively.

The contact angle has great influence on the normal load. Since the contact angle is critical to the pressure position, a moderate contact angle is beneficial to promote 


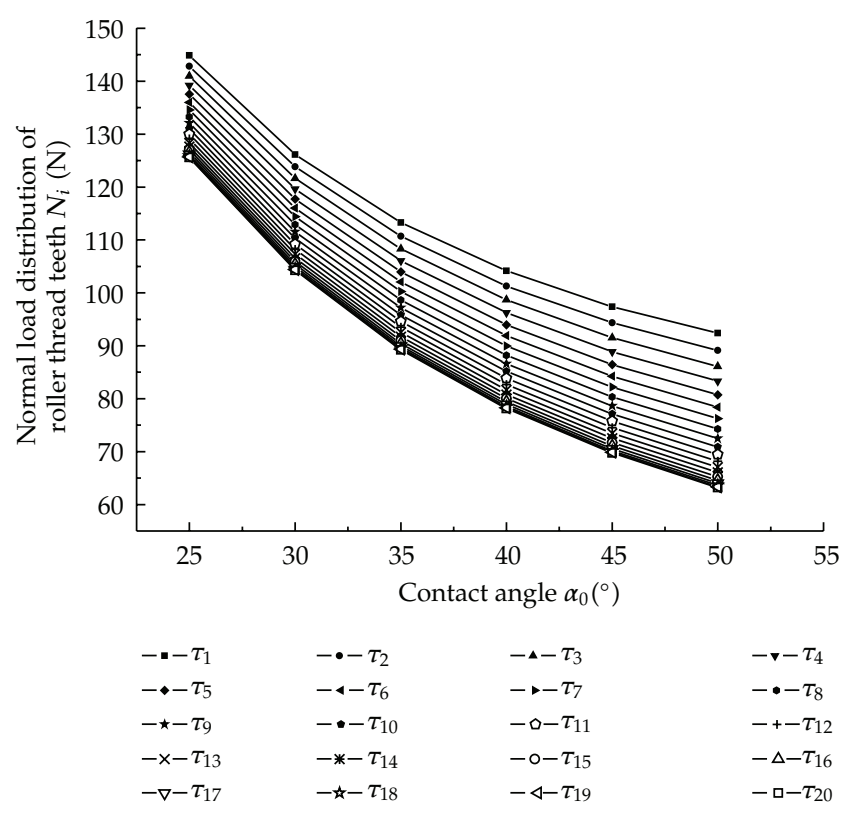

Figure 9: The relationship between contact angle and normal load.

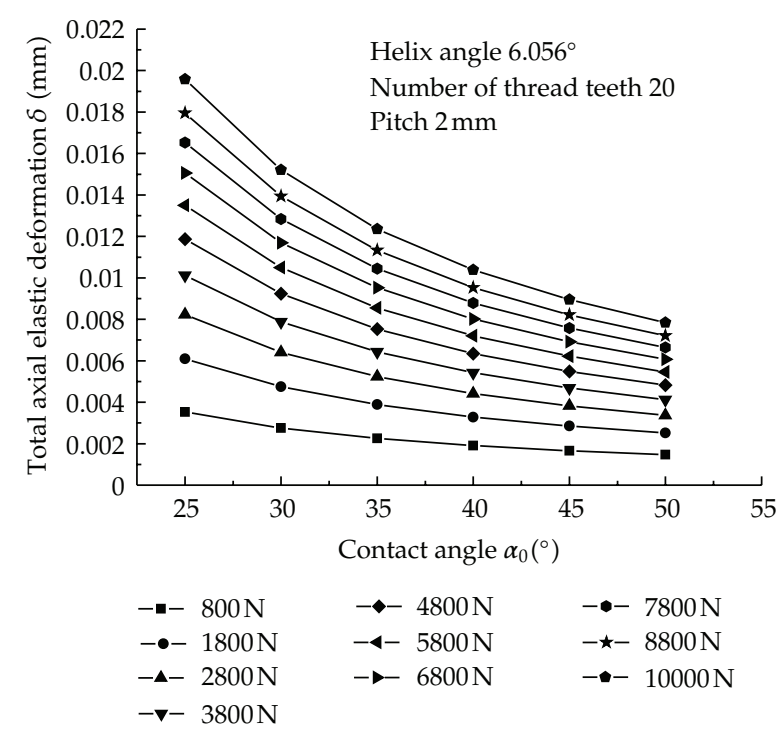

Figure 10: The relationship between contact angle and total axial elastic deformation.

transmission efficiency, carrying capacity, and roller's rotary fluency. As shown in Figure 9, the normal load on teeth of the roller thread decreases as the contact angle increases. And at the same operating conditions, the lower the normal load is, the lower the frictional moment is. Therefore, a larger contact angle should be selected. Similarly, it can be observed from Figure 10 that the total axial elastic deformation decreases with the increase of the contact angle, and the contact angle has stronger influence on the axial elastic deformation as the 


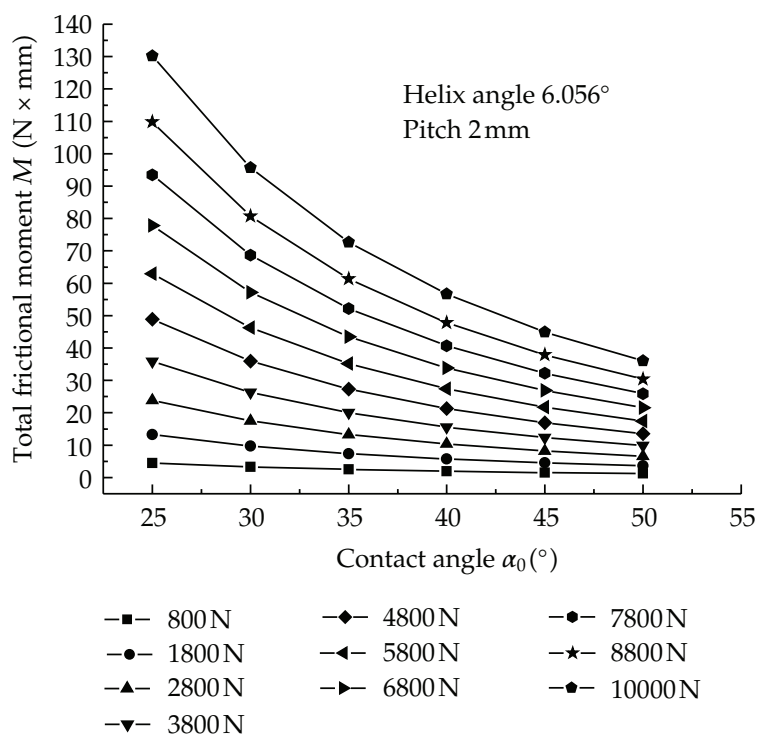

Figure 11: The relationship between contact angle and total frictional moment.

axial load increases. Hence, it is helpful to reduce the PRS's total axial elastic deformation and enhance its position accuracy if the contact angle is chosen properly.

\subsection{Relationship between the Contact Angle and the Total Frictional Moment}

From (4.7) and (4.8), it can be concluded that the contact angle is directly related to the frictional moment from the spinning sliding. The normal load on teeth of the roller thread can be changed with the variation of contact angle as shown in (3.17), which has indirect influence on the frictional moment caused by elastic hysteresis. The relationship between contact angle and total frictional moment is shown in Figure 11. It can be seen from Figure 11 that a lower axial load has less influence on total frictional moment. On the contrary, a higher axial load can give rise to a rapid decrease of total frictional moment as the contact angle increases. Thus, in order to improve transmission efficiency and reduce frictional moment, the contact angle can be increased properly. But the contact angle cannot be too large, because the decreasing trend of frictional moment and axial elastic deformation slows down. A larger angle is unfavorable to the engagement of screw threads. In general, the contact angle should be around $45^{\circ}$.

\subsection{Relationship between Helix Angle and Total Axial Elastic Deformation}

Equation (3.13) indicates that the helix angle is influenced by the starts of screw thread, $n_{s}$, the pitch, $p$, and the effective diameter of screw, $d_{s}$. From (2.12) and (2.15), the starts of screw thread or nut thread are decided after the effective diameters of screw, roller, and nut are known. Therefore only the pitch of screw is changed in the present study, and the influence of helix angle on total axial elastic deformation is analyzed. When the pitch is equal to $1 \mathrm{~mm}$, 


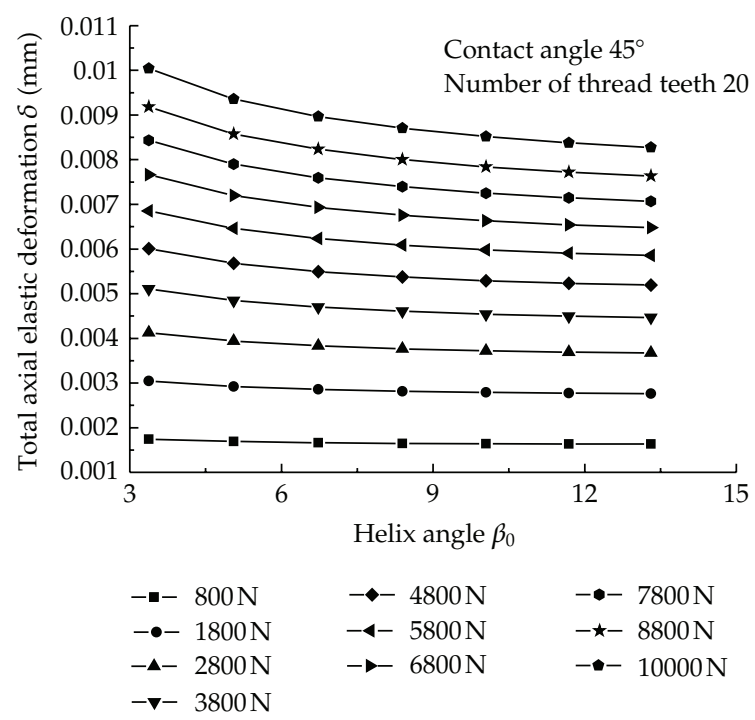

Figure 12: The relationship between helix angle and total axial elastic deformation.

$1.5 \mathrm{~mm}, 2 \mathrm{~mm}, 2.5 \mathrm{~mm}, 3 \mathrm{~mm}, 3.5 \mathrm{~mm}$, and $4 \mathrm{~mm}$, respectively, the corresponding helix angle is $3.037^{\circ}, 4.549^{\circ}, 6.056^{\circ}, 7.555^{\circ}, 9.043^{\circ}, 10.519^{\circ}$, and $11.981^{\circ}$, respectively.

As Figure 12 shows, the axial elastic deformation is slightly decreased by increasing the helix angle, and the higher the axial load is, the more obvious the decrease trend is, which is helpful to promote PRS's transmission performance. The lead and the feed speed will be increased due to a large helix angle. However, a relatively higher lead will increase difficulty of manufacturing, the error of thread processing, and the starting moment. Therefore, the deformation, torsion, and so forth should be considered to select suitable helix angle during PRS parameter design.

\subsection{Relationship between the Helix Angle and the Total Frictional Moment}

Frictional moments created at the two contact surfaces due to the existence of a relative velocity between two moving surfaces are examined to be a function of the operating condition. Figure 13 exhibits the variations in total frictional moments with the helix angle of the screw. because the value of $\beta_{0}$ computed by (3.13) is very small, the variation of helix angle that influences the normal load acting on teeth of the roller thread is also much less, and the influence of increasing the helix angle has very little effect on the total frictional moment. It can be observed from Figure 13 that the total frictional moment is nearly a straight line without obvious variation as the helix angle increases. However, the linear feeding displacement and speed of PRS are directly affected by increasing the helix angle. Therefore, it is believed that the helix angle can be determined according to PRS's operating conditions.

\subsection{Influence of Tooth Number of the Roller Thread on Total Axial Elastic Deformation}

The tooth number of the roller thread is a dominating parameter for PRS parameter design. If axial load is considered as a constant, the force acting on each tooth of the roller thread 


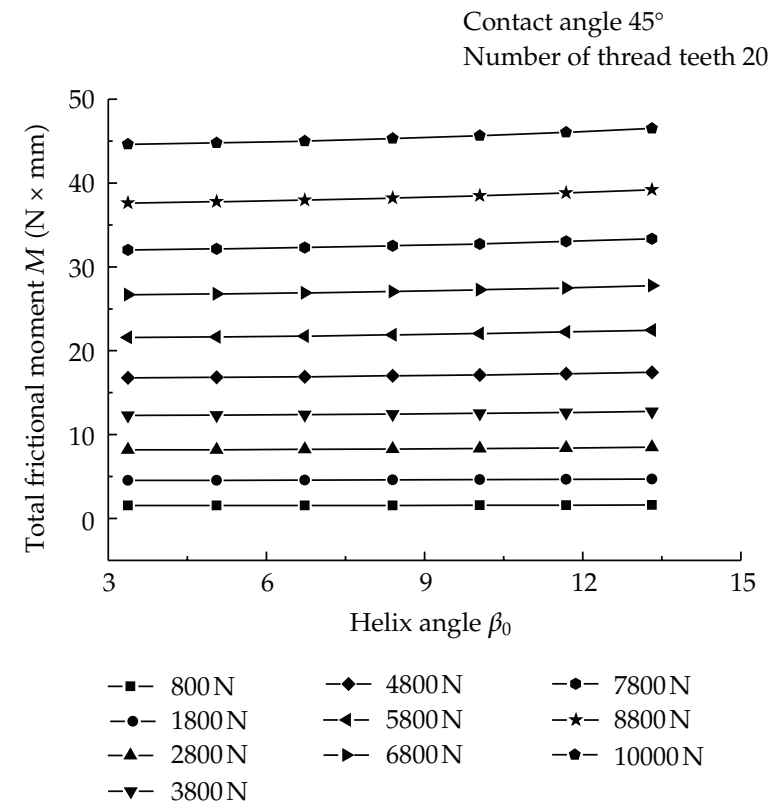

Figure 13: The relationship between helix angle and total frictional moment.

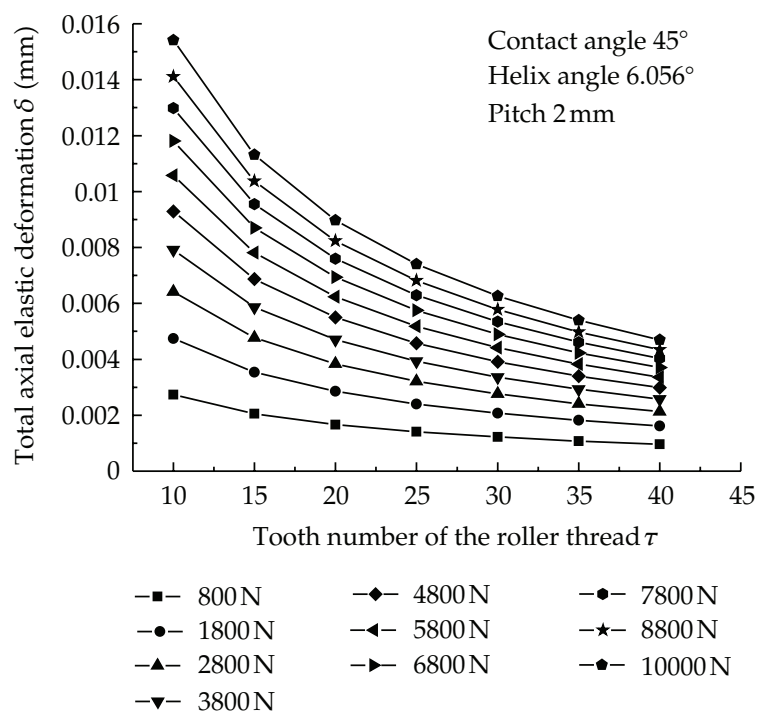

Figure 14: The relationship between the tooth number of the roller thread and total axial elastic deformation.

decreases when the tooth number of the roller thread increases. It can thus be concluded that the total stiffness of PRS can be promoted if the tooth number of the roller thread is increased. And as shown in Figure 14, the tooth number of the roller thread has great influence on the axial elastic deformation as the axial load increases. So the tooth number of the roller thread can be increased as appropriate according to the demand of carrying capacity and axial stiffness during PRS parameter design. 


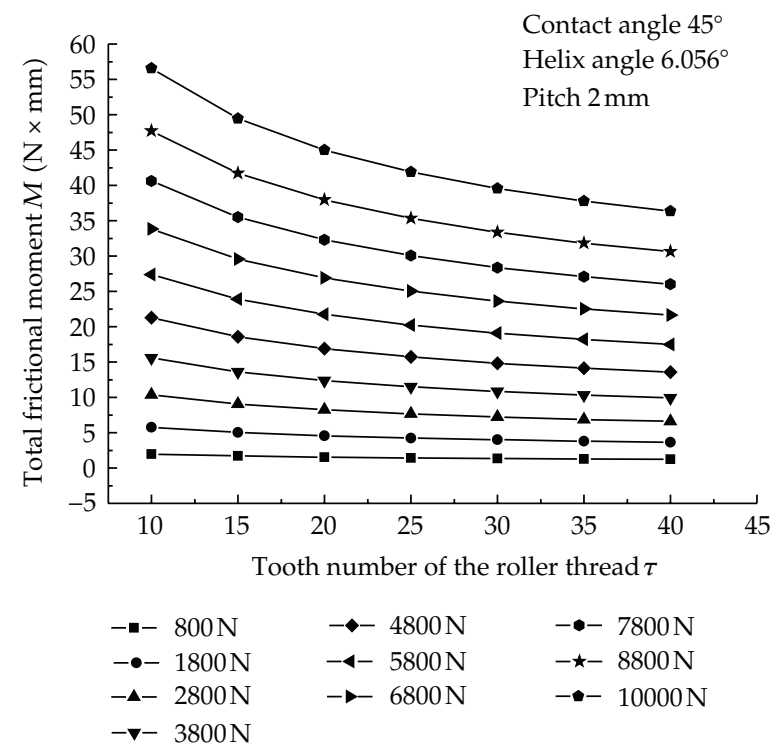

Figure 15: The relationship between the tooth number of the roller thread and total frictional moment.

\subsection{Influences of the Tooth Number of the Roller Thread on Total Frictional Moment}

In general, increasing tooth number of the roller thread of PRS will increase the frictional moment because more teeth is brought into contact. But it can be seen from Figure 15 that the frictional moment decreases as the tooth number of the roller thread increases. The reason is probably that the increase of tooth number of the roller thread will result in smaller normal load on each tooth, while the contact area of each tooth has no obvious variation when the axial load increases, as shown in Figures 6 and 7. The similar conclusion can also be obtained by (4.7) and (4.8). So it is beneficial to enhance the carrying capacity and reduce the total frictional moment if the tooth number of the roller thread is chosen properly.

\section{Conclusions}

(1) Due to the radial expansion deformation of nut threads, the axial stiffness on nut side is less than that on the screw side. The frictional moment, which is principally generated by roller's spinning sliding, increases with the increase of the axial load.

(2) The contact angle is a dominating parameter on the axial stiffness in high axial load. As the contact angle increases, the normal load on the rollers decreases dramatically, resulting in much more axial stiffness of the rollers and higher positioning accuracy of the PRS. A lower axial load has less influence on frictional moment. On the contrary, the frictional moment decreases more rapidly for higher axial load.

(3) Increment of the helical angle can increase the axial stiffness, which eventually improves the PRS performance and increases its positioning accuracy. However, the helix angle has no obvious influence on the frictional moment, and the value of helix angle can be determined according to the operating conditions of PRS. 
(4) Due to the load distribution, the more the tooth number of the roller thread is, the less the pressure on each tooth is. The tooth number of the roller thread has great influence on the axial stiffness for higher axial load. Therefore, the axial stiffness of PRS can be enhanced by increasing the tooth number of the roller thread. The total frictional moment decreases as the tooth number of the roller thread increases. So it is helpful to enhance the carrying capacity and reduce the total frictional moment if the tooth number of the roller thread is chosen properly.

\section{Appendix}

See Table 2.

\section{Nomenclatures}

$A_{s}: \quad$ Effective cross-section area of the screw

$A_{n}$ : $\quad$ Effective cross-section area of the nut

a: $\quad$ Half length of the major axis

$a_{r s}:$ Distance between the centers of the roller and the screw

$a_{r n}$ : Distance between the centers of the roller and the nut

$B$ : Curvature coefficient

$b$ : Half length of the minor axis

$d_{m}$ : Orbital diameter of roller

$C$ : A positive integer

$D_{s}$ : External diameter of screw

$D_{n}$ : External diameter of the nut

$D_{r}$ : External diameter of the roller

$d_{n}$ : Effective diameter of the nut

$d_{s}$ : Effective diameter of the screw

$d_{r}$ : Effective diameter of the roller

$E^{\prime}$ : $\quad$ Effective Young's modulus

$E_{s}$ : Young's modulus of the screw side

$E_{n}$ : Young's modulus of the nut side

$e$ : Eccentricity of contact ellipse

$F$ : Axial load

$F_{s r}:$ Axial tension of the screw

$F_{n r}$ : Axial compression of the nut

$F(\rho)$ : A function of curvature

$f_{h}$ : Sliding coefficient of friction

$f_{g}$ : Rolling coefficient of friction

$f_{s}$ : Elastic modulus of the elliptical contact points at the screw

$f_{n}$ : Elastic modulus of the elliptical contact points at the nut

$h_{a}^{*}: \quad$ Addendum modification of gear

$K(e)$ : Complete elliptic integral of the first kind

$L(e)$ : Complete elliptic integral of the second kind

$l_{s}$ : Axial displacement between the two consecutive screw threads

$l_{r}$ : Axial displacement between the two consecutive rollers thread 


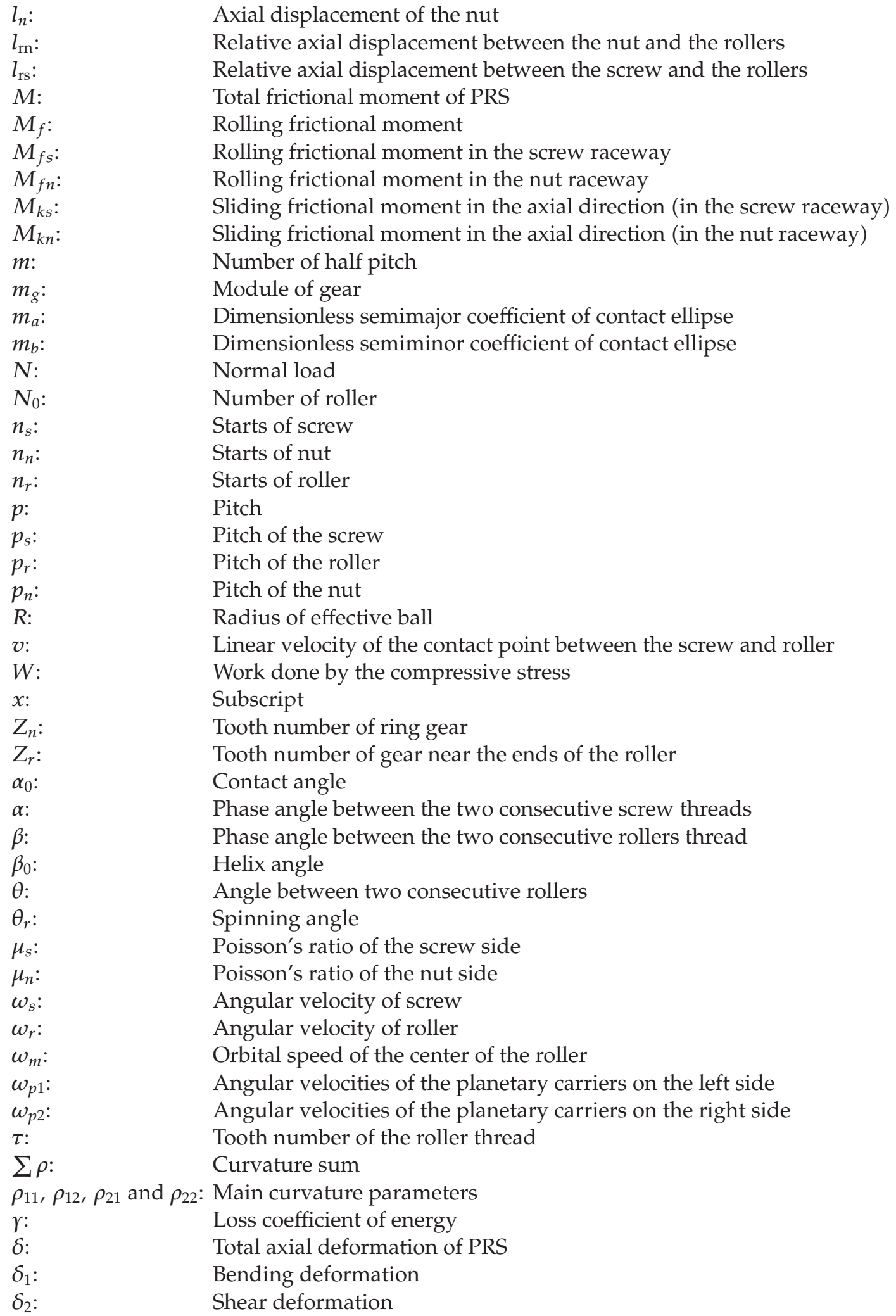


$\delta_{3}:$ Inclination deformation of the thread tooth

$\delta_{4}$ : Shear deformation of the thread tooth root

$\delta_{5}$ : Deformation of the screw thread tooth from radial shrinkage

$\delta_{6}$ : Deformation of the nut thread tooth from radial expansion

$\delta_{s}$ : Contact deformation in the screw raceway

$\delta_{n}$ : Contact deformation in the nut raceway

$\delta_{r}$ : Total axial deformation of the two consecutive teeth

$\delta_{s}^{\prime}$ : Total axial deformation of the screw side

$\delta_{n}^{\prime}$ : Total axial deformation of the nut side

$\delta_{h}$ : Hertzian contact deformation

$\delta_{s r}$ : Axial deformation of half pitch in the screw side

$\delta_{n r}$ : Axial deformation of half pitch in the nut side.

\section{Acknowledgments}

The research was supported by the National Natural Science Foundation of China (50975232 and 51275423), and Northwestern Polytechnical University Venture Seed Funding for Postgraduate (z2012052).

\section{References}

[1] P. C. Lemor, "Roller screw, an efficient and reliable mechanical component of electro-mechanical actuators," in Proceedings of the 31st Intersociety Energy Conversion Engineering Conference (IECEC '96), vol. 1, pp. 215-220, Washington, DC, USA, August 1996.

[2] D. E. Schinstock and T. A. Haskew, "Dynamic load testing of roller screw EMA's," in Proceedings of the 31st Intersociety Energy Conversion Engineering Conference (IECEC'96), vol. 1, pp. 221-226, Washington, DC, USA, August 1996.

[3] Q. Z. Jin, J. J. Yang, and J. L. Sun, "The comparative research on the static stiffness of ball screw and planetary roller screw," Mechanical Science and Technology, vol. 18, no. 2, pp. 230-232, 1999 (Chinese).

[4] M. Falkner, T. Nitschko, L. Supper, G. Traxler, J. V. Zemann, and E. W. Roberts, "Roller screw lifetime under oscillatory motion: from dry to liquid lubrication," in Proceedings of the 10th European Space Mechanisms and Tribology Symposium (ESMATS '03), pp. 297-301, San Sebastian, Spain, September 2003.

[5] A.S. Tselishchev and I. S. Zharov, "Elastic elements in roller-screw mechanisms," Russian Engineering Research, vol. 28, no. 11, pp. 1040-1043, 2008.

[6] S. A. Velinsky, B. Chu, and T. A. Lasky, "Kinematics and efficiency analysis of the planetary roller screw mechanism," Journal of Mechanical Design, vol. 131, no. 1, Article ID 011016, 8 pages, 2009.

[7] Y. Hojjat and M. Mahdi Agheli, "A comprehensive study on capabilities and limitations of rollerscrew with emphasis on slip tendency," Mechanism and Machine Theory, vol. 44, no. 10, pp. 1887-1899, 2009.

[8] M. H. Jones and S. A. Velinsky, "Kinematics of roller migration in the planetary roller screw mechanism," Journal of Mechanical Design, vol. 134, no. 6, Article ID 061006, 6 pages, 2012.

[9] M. H. Jones and S. A. Velinsky, "Contact kinematics in the planetary roller screw mechanism," in Proceedings of the ASME International Design Engineering Technical Conferences, 2012.

[10] Y. Zhao, J. Ni, and L. N. Lu, "Mesh calculation of roller screw pair," Machine Design, vol. 20, no. 3, pp. 34-36, 2003 (Chinese).

[11] Z. X. Wei, J. J. Yang, J. S. Zhu, B. Z. Yang, and W. Du, “Optimized analysis on structural parameter for planetary roller screw," Journal of Mechanical Transmission, vol. 35, no. 6, pp. 44-47, 2011 (Chinese).

[12] S. Ma, G. Liu, J. Zhou, and R. Tong, "Optimal design and contact analysis for Planetary Roller Screw," Applied Mechanics and Materials, vol. 86, pp. 361-364, 2011. 
[13] F. Chen, The Design and Research on Motive Accuracy for Two-Stage Planetary Roller Screw, Nanjing University of Science and Technology, 2009.

[14] X. Zhang, G. Liu, S. Ma, R. Tong, and H. Luo, "Study on axial contact deformation of planetary roller screw," Applied Mechanics and Materials, vol. 155-156, pp. 779-783, 2012.

[15] L. Gao, Design and research of planetary roller screw for precision application of the aerospace [M.S. thesis], Nanjing University of Science and Technology, 2012.

[16] P. A. Sokolov, O. A. Ryakhovskii, D. S. Blinov, and A. Laptev, "Kinematics of planetary roller screw mechanisms," Vestnik Mishinostroeniya, vol. 1, pp. 3-14, 2005.

[17] O. A. Ryakhovskii, D. S. Blinov, and P. A. Sokolov, "Analysis of the operation of a planetary roller screw mechanism," Vestnik Mishinostroeniya, vol. 4, pp. 52-57, 2002.

[18] T. A. Harris and M. N. Kotzalas, Rolling Bearing Analysis, Taylor \& Francis, 5th edition, 2006.

[19] J. Yang, Z. Wei, J. Zhu, and W. Du, "Calculation of load distribution of planetary roller screws and static rigidity," Journal of Huazhong University of Science and Technology, vol. 39, no. 4, pp. 1-4, 2011 (Chinese).

[20] Z. Zhang and K. M. Li, "Analysis on the accuracy of the electric cylinder with planetary roller screw," Manufacture Information Engineering of China, vol. 40, no. 19, pp. 72-74, 2011.

[21] J. J. Yang, B. Z. Yang, J. S. Zhu, and W. Du, "Effect of preload on axial deformation and friction of planetary roller screw," Journal of Mechanical Transmission, vol. 35, no. 12, pp. 16-22, 2011 (Chinese). 


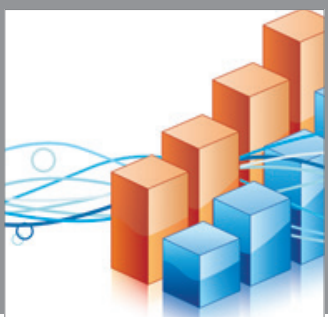

Advances in

Operations Research

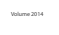

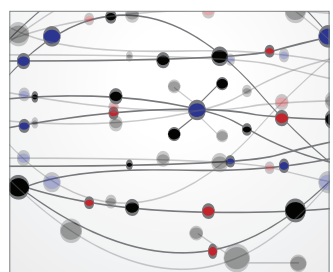

\section{The Scientific} World Journal
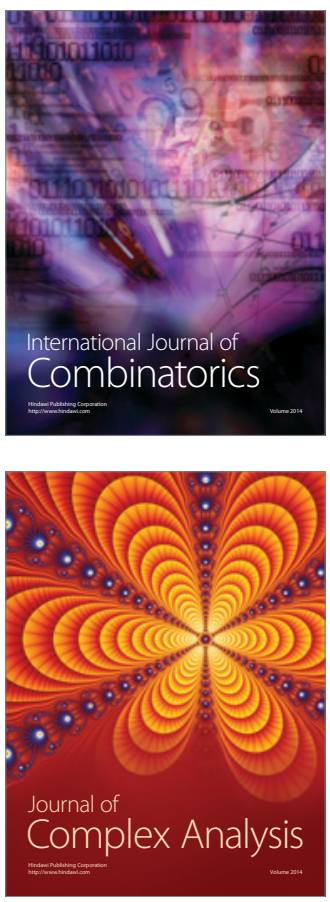

International Journal of

Mathematics and

Mathematical

Sciences
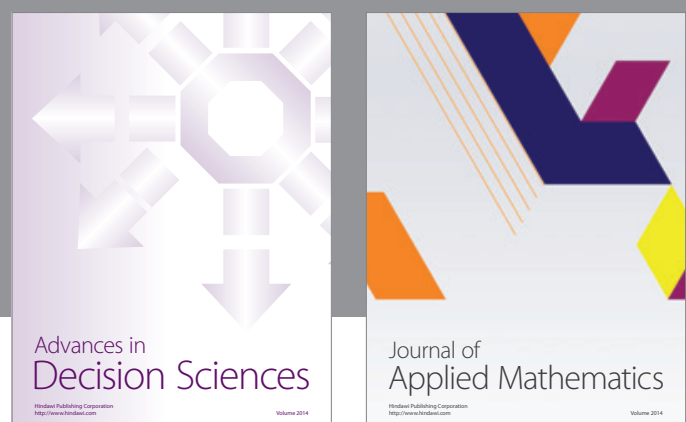

Journal of

Applied Mathematics
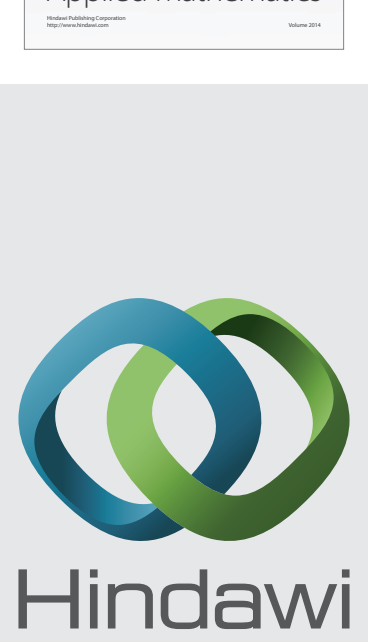

Submit your manuscripts at http://www.hindawi.com
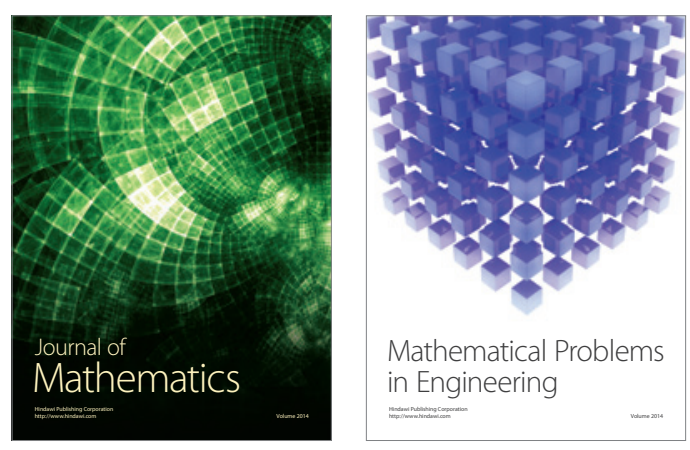

Mathematical Problems in Engineering
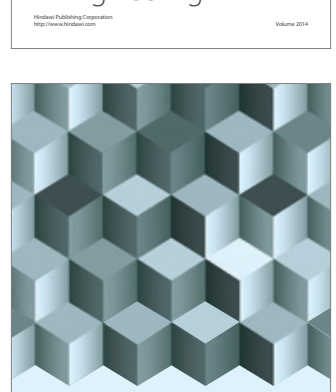

Journal of

Function Spaces
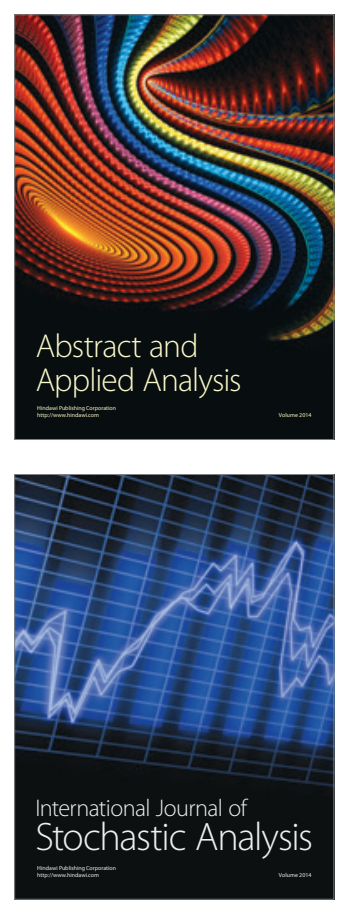

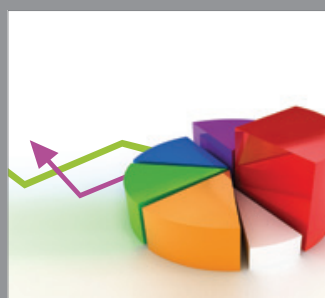

ournal of

Probability and Statistics

Promensencen
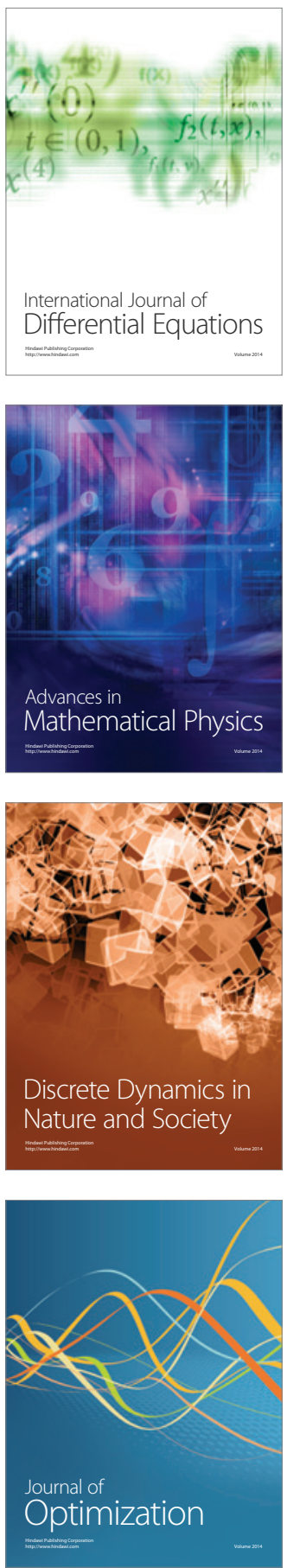